On Missed Encounters:

psychoanalysis, queer theory and the psychosocial dynamics of exclusion

\author{
Sasha Roseneil \\ Institute of Advanced Studies \\ University College London \\ Gower Street \\ London WCIE 6BT \\ s.roseneil@ucl.ac.uk
}

\begin{abstract}
This paper offers a discussion of the relationship between psychoanalysis and queer theory through the exploration of the author's personal experience of withdrawing from contributing to the 'Clinical Encounters in Sexuality' book. Tracing this back through the author's biographical history of confronting institutionalized mainstream British psychoanalysis, it provides an exploration of the psychosocial dynamics of the exclusion of unacceptable sexual identities, politics and theoretical perspectives. In so doing, it points towards the challenges posed by a more sociologically informed orientation, and to the potentialities of group analysis as a mode of psychoanalytic practice.
\end{abstract}




\title{
On Missed Encounters: psychoanalysis, queer theory and the psychosocial dynamics of exclusion
}

\begin{abstract}
'There are also a series of missed encounters in this book: The ten people whom we invited, accepted our invitation and withdrew from the project at a later date, without contributing a written piece. One person withdrew after submitting a piece. This also has the effect that there are more Lacanian voices present in section two.

We will leave it to readers to think about how the over-representation of one particular psychoanalytic discourse impacts on their reading experience' (Giffney, 20I7: 36, footnote II).
\end{abstract}

I have a confession to make. This is rather shameful: I am one of the missed encounters mentioned in Noreen Giffney's footnote. I agreed to write a piece for this volume, and I did not.

I remember the moment when I decided to renege on my commitment. I was on holiday on the beautiful subtropical island of Madeira in 2012. It was September, and we were staying in a charming little house, up a very steep hill. The late summer swimming was luscious. The water temperature was perfect. There was a laid-back café-bar above the lido, where you could sit and read and drink, bathing in ambient music, and periodically staring out to sea. It was hot and sunny and it should have been sublimely restful. But I had brought a hefty printout of contributions to Clinical Encounters in Sexuality with me. I was supposed to be reading them and then writing my piece for Section 3, which would offer commentary on the first two sections - "queer theories" and "psychoanalytic responses". It was already overdue. The task weighed on me, interrupting the sybaritic pleasures of my holiday. I needed a rest; I had been working hard all year. But this was the only time I could possibly write my chapter. I wanted to read the papers. I wanted to contribute to what I knew would be a groundbreaking book. Queer theory and psychoanalysis were two of my passions. But swimming in the Atlantic Ocean, drinking espresso and eating nata, are perhaps, another confession, more demanding and captivating passions.

And so I decided to withdraw. I rationalised this betrayal of my word in terms of my need for a break from work, from duty. It was an act of self-care. I might be breaking a promise to colleagues, and even sabotaging a unique opportunity to join an important debate, but it was the sensible thing to do.

And then, five and a half years later, invited to speak at a symposium about the book at the Freud Museum, I almost did it again'. Again, I had good reasons: too much work, more pressing writing deadlines, overdue articles promised to editors, not to mention a nearly finished book manuscript that I had not touched for months. And, even more powerfully activating my political superego, as a member of the University and College Union, which, at the time, was engaged in industrial action, I should not be undertaking 'voluntary activities', such as weekend working. I seriously contemplated withdrawing again, despite the

\footnotetext{
1 "What might clinical psychoanalysis learn from queer theories of sexuality?", Freud Museum, 28 February 2018. Podcast available at: https://www.freud.org.uk/2018/02/24/conference-what-might-clinicalpsychoanalysis-learn-from-queer-theories-of-sexuality/. This paper draws heavily on my talk for this symposium.
} 
generosity of the editors in giving me a second chance, and despite now having read the book and therefore knowing the significance of its intervention.

What is this repetition compulsion about? Why would I sabotage my contribution to this unique, field-defining book project? (It is so much more than just another book). Why had I had not made time to write my piece?

I could offer an explanation in terms of the contemporary condition of academic life - its intense pressures and the systemic over-commitment with which most of us live. I could add in a personal account of my own predispositions and choices that have enhanced these structural realities. And there would be much truth in such an account. But there is more to it than that.

I have been engaging with queer theory since the mid 1990s. Queer theory became a lens to frame my understanding of the transformations in gender and sexuality in which I was interested, changes being enacted by social movements, in popular culture and everyday life. I wrote about what I called the queer feminisms of Greenham Common (Roseneil, 2000a), and about the queering of intimate life - the decentring of the heterosexual couple, the proliferation of other ways of living and loving outside the co-residential, heterosexual couple formation, the valorisation of queer sexualities in popular culture, the new emphasis on friendship (Roseneil, 2000b, 2007; Roseneil and Budgeon, 2004).

Alongside this, I was developing an interest in psychoanalysis, particularly in its feminist and relational variants. I became increasingly dissatisfied with conventional sociological research methods and their assumption of a unitary rational subject, whose account of herself should be taken at face value. ${ }^{2}$ I knew that there was more going on for my interviewees, as they talked about love, friendship and intimacy, than they were consciously expressing in their discourse. I wanted to explore the unspeakable feelings of anger, pain, and loss, the conflicted desires and yearnings that sociological research on personal life was missing. Indeed, I became, over time, so excited by the possibilities of psychoanalytic insight into my abiding research questions - questions that I increasingly understood as psychosocial rather than as straightforwardly sociological - that I decided to train as a psychoanalyst. I wanted to get inside psychoanalysis, to learn the practice itself, to work with patients, not just read the theory, and attempt to apply it to my research.

And, because I wanted "the real thing", what I perceived to be the most rigorous, the most intensive, and, I have to admit, the oldest, most selective and prestigious training, I embarked upon a five times a week analysis. Sometime later I applied to the Institute of Psychoanalysis, the training arm of the British Psychoanalytical Society, which was then the only UK psychoanalytic institute recognised by the International Psychoanalytic Association.

I did this knowingly. The history of the Institute's treatment of lesbians and gay men was an open secret. Indeed, many friends and colleagues - sociologists, psychotherapists, feminists, lesbians - warned me against applying, as did my psychotherapist mother. It would be a damaging experience, they said. Psychoanalysis had not changed, at least in its institutionalised, British, elite formation. It was anti-feminist and homophobic to the core. There were, reputedly, no lesbian or gay members of the British Psychoanalytical Society. All that I knew.

\footnotetext{
${ }^{2}$ A crucial text for me in this journey was Hollway and Jefferson's (2000) book, “Doing Qualitative Research Differently".
} 
But I am strong-willed and ambitious, and I love the challenge of the forbidden. I did not think it could hurt me. After all, I had been out since I was I7. I remembered the shame and the secrecy of my teenage years, and the struggles of the 1980s: the relentlessly homophobic press, AIDS, Section $28^{3}$, verbal abuse and physical violence from men on the streets, the hard-to-find lesbian clubs in the seedy back rooms of pubs on Monday nights. I knew it was not like that anymore: the world was changing, indeed that was what my work was about. The Labour government of 1997 had ushered in a new era of 'lesbian and gay friendly' law and policy - same-sex sexualities were being normalized across Europe (Roseneil et al, 2013). It was 2004, the year that civil partnerships for same-sex couples were introduced.

I was rejected by the Institute. Not absolutely and definitively - I was told that I might reapply at some, undefined, point in the future. It was the psychoanalytic version of 'revise and resubmit', but without the detailed feedback on what to revise.

Yet, I had a good idea what was wrong with my application. I admit that it was, perhaps, premature - I had been in five times a week analysis for less than a year. I now know that people often apply and are rejected multiple times before securing entry to the Institute, and that they can have to spend years in analysis before being deemed ready to train.

But really the core of the problem was, I believe, who I am: a lesbian and a sociologist. One characteristic alone would have been difficult, and the former was very likely still then grounds for exclusion as evidencing 'disturbance of mind or development'; ; but the two together made me an impossible candidate.

The killer question in the first interview was, "So, can you tell me how you understand your sexuality?"

I was surprised it was so upfront. I took a deep breath. My reply began, "I am going to assume that you would ask someone who identified as heterosexual that question", and I set off down a biographical narrative route, telling the story of how I came to see myself as a lesbian, of falling in love with a girl in the year above at school, a tale of teenage angst, passion, heartache, sexual experimentation, and moments of profound social exclusion and deep-seated fear of the life of loneliness and isolation that stretched ahead. I talked about the joy of finding Women's Press books that conjured the possibilities of lesbian community, amidst a dearth of cultural representations, and of arriving at the Women's Peace Camp at Greenham Common and realising that I was far from alone in my dangerous desires and burgeoning identity.

That wasn't what the analyst wanted to hear about. "No", she said. "I mean, how do you understand the origin of your sexuality?"

I drew in another deep breath, and paused.

\footnotetext{
${ }^{3}$ Section 28 of the 1988 Local Government Act prohibited local authorities (and hence schools, libraries, etc) from "promoting" homosexuality and "pretended family relationships".

${ }^{4}$ The 2010 Equality Act made discrimination on the grounds of sexuality illegal, and prompted the beginning of a process of reckoning with the history of exclusionary practices within British psychoanalysis. In 2012, members of the British Psychoanalytic Council, including the British Psychoanalytical Society/ Institute of Psychoanalysis, signed up to a statement opposing discrimination on the basis of sexual orientation, and stating that they do "not accept that a homosexual orientation is evidence of disturbance of the mind or in development" https://www.bpc.org.uk/rethinking-our-approach-sexualities.
} 
I am not sure that I believe in origins, in causes, I replied, not of sexuality, not of anything really. Things are much more complex than that. I'm ontologically too formed by postmodernism, too far removed from causal ways of thinking, to be able to answer that question, I'm afraid. And I certainly don't see sexuality like that. I think sexuality is the complex product of many influences - historical, biographical, social, family, cultural... I could expand on that, offer a theory of sexuality, if that's what you want?

It wasn't. We moved on to the next question.

The second interview sealed my fate with questions about my parents. I had written long essays about them as part of the application, about my relationships with each of them, and about their relationship with each other. They had met in Russia in the early 1960s. Neither were pro-Soviet, but they were socialists and internationalists, and they met at an international peace conference in Moscow, at which my father was arrested for protesting against Russian nuclear weapons. The interview stalled around the relationship between socialism, sociology and psychoanalysis.

Was I a socialist, the analyst asked, like my parents?

It was 2005. What was socialism in 2005? Did it still exist? I had studied the end of the Cold War, and recently I had been researching intimate citizenship under socialism, and after, in Bulgaria. My teenage identification had been with anarchism and feminism, not with socialism. In 1997, after 18 years of Conservative government, I had believed that things could only get better under the new Labour government, and I was still arguing with my ultra-critical/ disillusioned friends and colleagues that they had. Was I a socialist? Compared with many, yes; uncritically, nostalgically, no. Would I disavow the core values of the socialism of my parents and grandparents: a belief in redistribution, equality, the NHS, internationalism, the struggle against racism, and for peace and global justice? Absolutely not.

But socialism and psychoanalysis are incompatible, he said.

Are they? I replied. I don't think so. I was getting irritated now. I'm hardly the only person who thinks that - what about the Frankfurt School, Fromm, Adorno, Horkheimer, Reich.

And you're a sociologist?

Yes.

Sociology and psychoanalysis aren't compatible, are they?

Now that was a tricky question. In many ways he was right. Sociology as a discipline has taken little interest in psychoanalysis. ${ }^{5}$ Very few Anglophone departments of sociology have any faculty members with an interest in psychoanalysis. And it was certainly true that psychoanalysis has shown little interest in sociology.

But I felt the need to stake a claim to the possibility: there have been some influential sociologists, or at least social theorists, of a psychoanalytic persuasion. I gave some examples: Adorno, Horkheimer (again), Talcott Parsons, Neil Smelser, Nancy Chodorow, lan Craib, Jessica Benjamin. I was running out of names, and there did not provoke any sense of recognition in my interviewer. And there's me. I think that sociology and psychoanalysis

\footnotetext{
${ }^{5}$ See Chancer and Andrews (2014).
} 
can work together. I'm doing research in which I am using psychoanalytically-informed methods.

I lost that interview too. I was a lesbian and a sociologist, and I couldn't be a psychoanalyst. At least, it seemed that I could not become a BPS/ Institute, IPA-recognised psychoanalyst.

I knew very well that this was just one version of psychoanalysis, the elite, establishment, conventional psychoanalysis that had successfully claimed the exclusive right to the title of psychoanalyst in Britain. I had known better than to challenge my interviewers to discuss feminist and relational psychoanalysis, or queer theoretical engagement with psychoanalysis. None of that was BPS/ Institute psychoanalysis.

I had expected to be rejected. I wasn't surprised. But nonetheless it hurt - a little. It made me angry - a little. And it left its mark - a little, the small rejections, hurts, scars that constitute a queer life.

As it transpired, just a few weeks after my rejection by the Institute of Psychoanalysis, I found my way to the annual Introductory Weekend in Group Analysis, at the Institute of Group Analysis (IGA), and I was blown away by the experience. It was moving, immersive, alive, volatile, intellectually stimulating, and, above all, collective. It wasn't just me and one other person in a room together, interminably, boringly and irritatingly locked in the prison of my analyst's paradigm. It was a social, a group experience. It did, of course, once I embarked upon my own group analysis and started training, become, at times, interminable, boring and irritating, because other people are, at times, all of those things, as am I.

But group analysis rests on the twin pillars of psychoanalysis and sociology - from Freud and the Frankfurt School, through SH Foulkes and Norbert Elias - together and in tension - the psycho and the social, the individual and the group, the personal and the political, always mutually entangled, always conflictual. I was hooked.

And so I decided to train as a group analyst. Neither my profession nor my sexuality were problematized by the IGA. Sociology was an esteemed discipline, seen as foundational to the field, even if, in actual fact, its implications for group analytic theory and practice remain radically under-explored. And a handful of gay men and lesbians had preceded me in training, and I trained alongside several more. Indeed, one of my supervisors was a highly respected gay group analyst and theorist of sexuality in groups.

Eight years later I was qualified, and could call myself a group analyst. I had learnt a lot about myself, about people and groups, about relationality, intersubjectivity, and being with others. Perhaps above all I had learnt about the potency of belonging and not-belonging - about the deep psychosocial dynamics of cultural value and normativity, of inclusion and exclusion, and how we re-enact and are shaped by them.

Whilst non-normative sexualities have yet to be extensively written about in the group analytic literature, I experienced an openness to diversity, to the exploration of difference, and for transformative encounters in group analytic practice. The group is, I believe, a space of queer potentiality and multiplicity, of challenge to the couple-norm, which makes it radically different from the dyadic encounter of analyst and analysand. Positions, identities and desires are piqued, challenged, played with in the group - or they can be, if the group analyst can tolerate, contain, enjoy the fluidity and queerness of human experience. There is a public-ness and sociality to group analysis that is the antithesis of psychoanalysis. Some think that this means that group analysis is not able to go deep, that it is unable to tackle the complexities of sexuality, the dark aspects of desire, the anti-normativity and anti-sociality of 
sex, and intensities of intimacy between two people. I disagree. But that is for another paper - the one I might have written had I contributed to this book, had I not excluded myself.

So, why did I do that? I am more willing now than I was in 2005 , when challenged by the Institute interviewer, to think about causes and origins. In 20I2, on that holiday in Madeira, I was nearing the end of my training as a group analyst. I was not a psychoanalyst, or even a psychoanalytic candidate. Indeed, I had been rejected by psychoanalysis. The scar was small, but it was there. I was not pure. I was not engaged in the real practice that was being brought into dialogue with queer theory in this book.

And, I will confess, there was also a part of me that doubted if I was really doing queer theory. I was too much of a sociologist, too engaged with people's lives, with the everyday, complex ordinariness of practices of intimacy and sexuality, with understanding social change. I was not really a Queer Theorist. I was, I am, a social scientist, not a humanities scholar, and in the cultural hierarchy of critical academia, the humanities trump the social sciences.

Not that Noreen and Eve specified, in any way, that they wanted either "proper" pure BPS/ Institute psychoanalysis, or Queer Theory untrammelled by social science. But such is the power of cultural value. It gets inside us, and we exclude ourselves, even those of us who like to think that we know better.

I wonder what the story was with the other nine missed encounters. Nine is the perfect size for an analytic group.

\section{References}

Chancer, L. and J. Andrews (2014) The Unhappy Divorce of Sociology and Psychoanalysis Palgrave Macmillan.

Hollway, W. and T. Jefferson (2000) Doing Qualitative Research Differently London: Sage.

Roseneil, S (2000a) Common Women, Uncommon Practices: the queer feminisms of Greenham London: Continuum.

Roseneil, S. (2000b) 'Queer Frameworks and Queer Tendencies: Towards an Understanding of Postmodern Transformations of Sexuality', Sociological Research Online, vol. 5, no. 3, I-I9.

Roseneil, S. (2007) 'Queer Individualization: The Transformation of Personal Life in the Early 2 Ist Century', Nora - Nordic Journal of Feminist and Gender Research, vol. I5, no. 2-3, 84-99.

Roseneil, S. and S. Budgeon (2004) 'Cultures of Intimacy and Care Beyond "the Family": Personal Life and Social Change in the Early 2 I st Century', Current Sociology, vol. 52, no. 2, Pp. 135-59.

Roseneil, S., I. Crowhurst, T. Hellesund, A.C. Santos and M. Stoilova (20I3) 'Changing Landscapes of Heteronormativity: The Regulation and Normalization of Same-Sex 
Sexualities in Europe', Social Politics: International Studies in Gender, State \& Society, vol. 20, no. 2, $165-99$. 